\title{
Afinidade e estranhamento
}

Gabriel Cohn

E ALANDo do seu velho amigo Michael Löwy, no livro a ele dedicado, Roberto Schwarz assinala, numa passagem especialmente expressiva do seu belo depoimento, a singular combinação que desde cedo marcou a conduta de vida do "grande homem" (como brinca): "um arranjo incomum, em que estranhamente o dever, a fantasia e a revolução parecem não se opor uns aos outros, mas sim colaborar". Com isso, ele oferece o mote para a leitura desse conjunto de ensaios, em que colegas e amigos se reúnem para examinar, com simpatia crítica, uma trajetória realmente singular. Brasileiro-europeu, surrealista-socialista, românticorevolucionário, disciplinado-libertário, ateu-religioso; a lista de contrastes poderia estender-se muito - desde que em nenhum momento se perca de vista que os termos contrastantes sempre devem comparecer juntos, e inseparáveis, numa alquimia de cujo segredo Michael parece ser o único detentor.

Falei em alquimia, e isso me leva sem mais ao termo que vários dos colaboradores no livro identificam como aquele que melhor exprimiria a orientação do pensamento de Michael quando dá curso à sua infatigável curiosidade sócio-político-histórica-cultural (que já resultou em dezenas de livros e incontáveis artigos, grande parte deles traduzidos em 25 idiomas - nada mal, para quem certamente despreza o discurso da "produtividade"): a idéia de "afinidades eletivas". Deixando-se de lado as fontes dessa idéia no pensamento de Löwy (na cabeça dele, a coisa certamente vai além de Max Weber), vale a pena assinalar que o caráter fino e flexível da noção de afinidades eletivas (quando permite escapar ao estabelecimento de laços causais rígidos, em proveito da atenção às ressonâncias mútuas entre orientações de pensamento e de conduta que percorrem cada qual a sua via própria) não poderia deixar de fascinar um autor sempre em busca das formas mais sutis e compreensivas (no sentido de estabelecer relações entre complexos de significados e não pontoa-ponto) no interior da sociedade.

Qual sociedade? A brasileira? Tal ou qual entidade européia? A americana, no sentido amplo? A resposta é: cada qual no seu momento, como representante de algo que a transcende e que se projeta no horizonte como possibilidade não cumprida a sempre ser evocada como tal: a sociedade verdadeira, a associação livre de homens e mulheres livres. Utopia, portanto, como já indica o título do livro, que joga com esse contraponto da particularidade e da universalização possível ao falar das "utopias de Michael Löwy". Mas esse paradoxo ambulante não olha só para o horizonte, com pose de Platão no quadro de Rafael. Se ele ocupasse um lugarzinho naquele quadro (e se estivesse em Roma na época, poderia ser encontrado no ateliê do pintor, entrevistando-o), Michael provavelmente estaria olhando com uma ponta de troça para as atitudes de Platão e também de Aristóteles, tão rigidamente contrapostas. A complexa tipologia de caracteres desenvolvida nos guetos judaicos da Europa Central e Oriental inclui uma figura, a do luftmensch, aquela criatura que flutua no ar, na atmosfera rarefeita das suas 
idéias e fantasias, utópicas talvez. Se fosse possível construir um luftmensch com os pés solidamente postos no chão da história presente, chegaríamos mais perto da feição de Michael Löwy, esse cosmopolita ateu impregnado até a medula pelo que de melhor o judaísmo ofereceu ao mundo.

Mas, afinal, o que faz esse homem além de tecer utopias com os fios do seu "marxismo insubordinado" (como também diz o título do livro)? Primeiro, não começou, ao contrário do que sua obra posterior poderia sugerir, no caminho do tratamento sofisticado de temas da sociologia do conhecimento (o que inclui a análise de movimentos culturais e políticos), mas por um artigo, característica mescla de modéstia e arrojo, na Revista Brasiliense de Caio Prado Júnior, sobre a ideologia de lideranças sindicais. Ali se encontra o seu primeiro trabalho de campo, feito por militante engajado, talvez por inspiração do contato com o sociólogo Azis Simão, pioneiro na área. Antes disso, já dera prova da atenção do verdadeiro militante às diversas dimensões das lutas sociais à sua volta, ao ser um dos que mais fortemente encorajaram Florestan Fernandes a se empenhar naquilo que acabou marcando a trajetória do grande mestre: a grande campanha em defesa da escola pública, ameaçada pelas forças retrógradas que Paulo Duarte também combatia na revista Anbambi. Tudo isso certamente contribuiu para essa singular mescla de pesquisador exigente (afinal, de grandes autores do século XX a cidadãos comuns, ninguém sabe quantos ele já entrevistou, nem quantas bibliotecas e arquivos percorreu para tarefas insólitas e engenhosas, como a de reexaminar fontes de Max Weber na elaboração da sua obra sobre ética religiosa e capitalismo) com o vôo da imaginação e o aprofundamento teórico no momento certo.

Ao longo dos dezenove textos do livro, entre os quais o prefácio de Leonardo Boff, vai-se descortinando a diversidade da obra de Löwy. Neles, discutem-se desde os dilemas da condição social do intelectual até a relação de Michael com grandes figuras do marxismo europeu, como fazem Olgária Matos, no caso de Walter Benjamin, e Maria Elisa Cevasco, no de Raymond Williams, interlocutor de Löwy - a propósito, Marcelo Ridenti lembra que ele nunca se deteve sobre pensadores brasileiros e pouco sobre os latino-americanos, e vincula isso à conquista de posição acadêmica de relevo na França, escapando da condição subalterna de especialista em coisas exóticas -, passando pela sua presença no marxismo brasileiro e no latino-americano e pela sua atenção às novas relações que se foram estabelecendo ao longo do século entre movimentos revolucionários e religiosos. Seria fora de propósito nem sequer insinuar uma exposição do conjunto dessas contribuições. Mais vale recolher aqui e ali alguns temas, que permitam ilustrar sua diversidade e riqueza.

No seu exame da questão da inserção social dos intelectuais, Wolfgang Leo Maar, que nesse grupo representa bem a posição marxista mais severa, embora flexível no momento certo, usa em passagens centrais do seu argumento o conceito de possibilidade objetiva, colhido por Löwy na linhagem WeberLukacs-Goldmann, e que desempenha no seu pensamento papel que talvez possa ser visto como complementar ao de afinidades eletivas. O mesmo conceito está presente em vários outros ensaios, num testemunho à sua importân- 


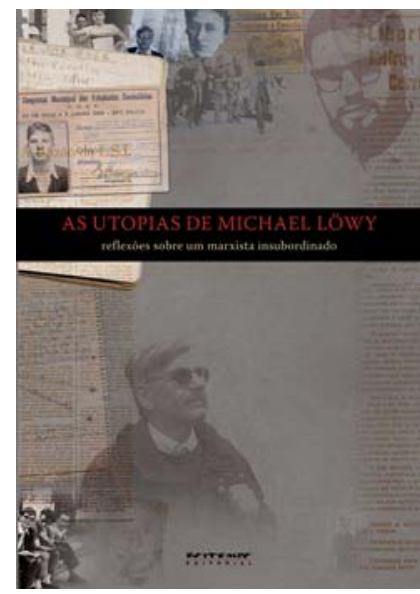

JINKINGS, Ivana; PECHANSKI, João Alexandre. (Org.) As utopias de Michael Löwy. Reflexões sobre um marxista insubordinado.

Prefácio de Leonardo Boff. São Paulo: Boitempo Editorial, 2007. 195p.

cia, como ocorre quando Alfredo Bosi se vale justamente dele para reconstruir o tema da Teologia da Libertação e localizar o diálogo de Michael com ela. É como se, no conjunto, se apontasse para uma concepção robusta de utopia, que envolvesse $\mathrm{o}$ intrincado jogo entre aqueles dois conceitos e, ao fazê-lo, também conferisse conteúdo à idéia, igualmente central, de crítica - não qualquer crítica, mas a revolucionária, que demonstra os limites do estado de coisas vigente para mudá-lo.

É claro que o problema da realização histórica do socialismo impregna de alguma maneira o conjunto dos textos. Especialmente, como seria de esperar, no ensaio de Isabel Loureiro sobre a grande heroína de Michael, Rosa Luxemburg (sua referência desde os velhos dias da Liga Socialista Independente, com Hermínio Sacchetta). Nesse contexto, emerge outro tema caro a ele, o da alternativa histórica socialismo ou barbárie. Embora essa interpretação não se encontre nesses termos em Isabel, creio ser plausível afirmar que, para Rosa, a iminência que ela entendia inexorável da crise final do capitalismo não significava (ao contrário dos que vêem nela mero "economicismo") a solução sem mais do problema histórico posto pela possibilidade real da barbárie. Importa, aqui, que é exatamente a crise do capitalismo sem a solução socialista que constitui a barbárie - e que precisamente por isso para ela se torna imperativa a construção imediata da alternativa revolucionária socialista. Mas, assinala Isabel, na sua fase atual o capitalismo, ainda que não em crise aberta, segrega barbárie por todos os poros. Michael não é desatento a isso, como demonstram as suas incursões seguidas e diferenciadas na busca de possibilidades contemporâneas de constituição de formas não-capitalistas de sociedade, incluindo-se nisso a posição diante do problema ambiental planetário. Várias contribuições no livro aludem, por ângulos diversos, a essa busca de modos contemporâneos de dar conteúdo concreto ao confronto com o capitalismo.

Recorrendo a uma metáfora usada por Michael com referência à situação do pintor - a de que se vê mais amplo a partir do mirante mais alto, e de que, historicamente, o ponto mais alto é o do proletariado -, Flávio Aguiar presta-lhe elegante homenagem, ao realçar mais o pintor do que o mirante (que também recebe míopes). Afirma ele que "Löwy percebeu e acolheu, em seu pensamento, o poder inovador desse encontro entre uma teologia libertada das suas peias opressoras [...] e as sendas abertas pelos novos caminhos trilhados pelo pensamento libertário, revolucionário ou transformador $[\ldots]$. Somente os grandes 
pintores são capazes de intuições tão fecundas quanto belas". A escolha segura do mirante, o rigor na visada, a intuição fecunda e bela. Eis um bom retrato de Michael Löwy.

Gabriel Cohn é professor titular do Departamento de Ciência Política da Faculdade de Filosofia, Letras e Ciências Humanas da USP. @-gcohn@uol.com.br 